\title{
TPF 3.0 do tworzenia wykresów przemian fazowych austenitu w stalach w warunkach spawalniczych CTP $_{\mathrm{c}}-\mathrm{S}$
}

\author{
TPF 3.0 for the CCT diagram determination \\ of austenite phase transformation in steels \\ in welding conditions
}

\section{Streszczenie}

W artykule scharakteryzowano warunki spawalnicze wynikające z zasadniczych różnic pomiędzy cyklem cieplnym klasycznej obróbki cieplnej a cyklem cieplnym spawania. Przedstawiono metodykę badania przemian fazowych austenitu w stalach w warunkach oddziaływania spawalniczych cykli cieplnych. Omówiono przeznaczenie, możliwości i procedurę postępowania w programie TPF $3.0 \mathrm{w}$ odniesieniu do edycji wykresów przemian fazowych austenitu w warunkach spawalniczych $\mathrm{CTP}_{\mathrm{C}}-\mathrm{S}$. Przedstawiono porównanie wykresu $\mathrm{CTP}_{\mathrm{C}}-\mathrm{S}$ z wykresem $\mathrm{CTP}_{\mathrm{C}}$ dla stali konstrukcyjnej S355JR.

\section{Abstract}

The article presents the welding condition resulting from the difference between the thermal cycle of standard heat treatment and a welding thermal cycle. The methodology of phase austenite transformation examination in steels in the condition of welding thermal cycles is explained. The use, ability and operation procedure -of TPF software (ver. 3.0) with reference to the determination of CCT (Continous Coding Transformation) diagrams of phase austenite transformation in steels in welding conditions are presented. The welding-related CCT and CCT diagrams for structural steel S355JR grade are compared.

\section{Wstęp}

Jedną z podstawowych charakterystyk stali, niezbędnych do określenia ich spawalności przy użyciu danej technologii łączenia, są wartości temperatury krytycznej (tj. wartości temperatury początku i końca) przemian fazowych austenitu zachodzących w stalach w stanie stałym podczas nagrzewania i chłodzenia.

Specyfika warunków spawalniczych towarzyszących procesowi nagrzewania i chłodzenia spawanego elementu powoduje, że występują zasadnicze różnice w przebiegu i charakterze cyklu cieplnego spawania w porównaniu z cyklem tradycyjnej obróbki cieplnej, co przedstawiono na rysunku 1.

Dr hab. inż. Mirosław Łomozik, prof. IS., mgr inż. Adam Pilarczyk - Instytut Spawalnictwa, Gliwice.

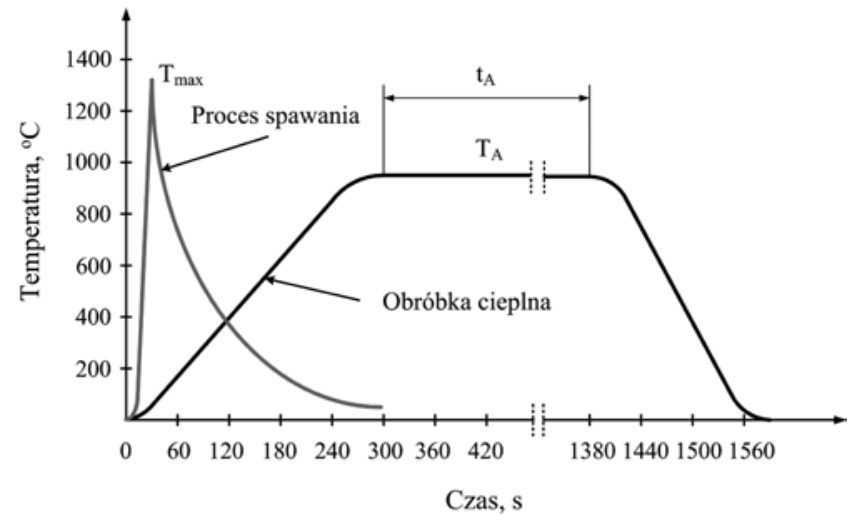

Rys. 1. Porównanie przebiegu cyklu cieplnego spawania z cyklem tradycyjnej obróbki cieplnej: $T_{A}-$ temperatura austenityzacji, $t_{A}$ - czas austenityzowania [1, 2]

Fig. 1. Welding thermal cycle compared with traditional heat treatment cycle: $\mathrm{T}_{\mathrm{A}}$ - austenitisation temperature, $\mathrm{t}_{\mathrm{A}}$ - austenitisation time $[1,2]$ 
Cykle cieplne spawania różnią się od cykli obróbki cieplnej [2]:

- bardzo dużą szybkością nagrzewania i chłodzenia w obszarze strefy wpływu ciepła (SWC),

- bardzo krótkim czasem wytrzymania w temperaturze maksymalnej,

- nakładaniem się dwóch lub więcej cykli cieplnych podczas spawania wielowarstwowego.

Ze względu na te różnice wartości temperatur krytycznych przemian austenitu w stalach są przedstawiane na wykresach typu Czas - Temperatura - Przemiana przy chłodzeniu ciągłym, sporządzanych dla warunków spawalniczych - w skrócie CTP ${ }_{\mathrm{C}} \mathrm{S}$.

\section{Badania przemian fazowych w stalach w warunkach spawalniczych}

W Instytucie Spawalnictwa w Gliwicach przemiany fazowe w stalach w warunkach oddziaływania cykli cieplnych spawania bada się metodą symulacyjną na stanowisku pomiarowym, które przedstawiono na rysunku 2.

Metodyka badania przemian fazowych opiera się na równoczesnym wykorzystaniu trzech metod pomiarowych: dylatometrycznej, magnetometrycznej oraz analizy termicznej. Podczas badań dokonuje się zapisu trzech sygnałów pomiarowych w postaci tablicy punktów pomiarowych: dylatacji materiału prób$\mathrm{ki}$, zmiany strumienia magnetycznego i temperatury

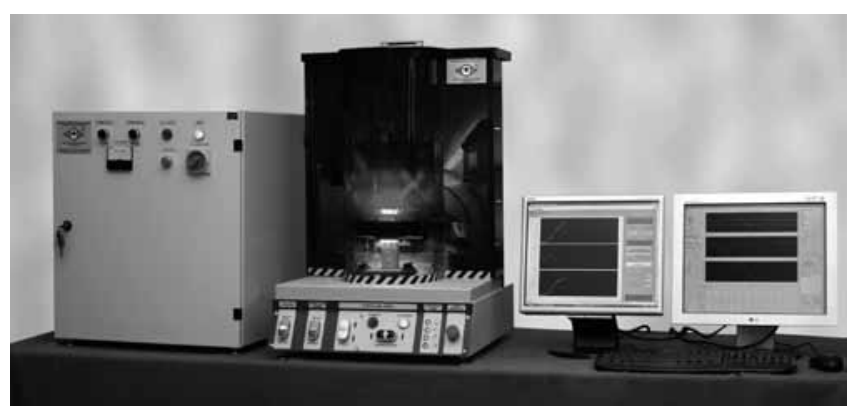

Rys. 2. Stanowisko do badania przemian fazowych w stalach w warunkach spawalniczych w Instytucie Spawalnictwa w Gliwicach Fig. 2. Stand for testing phase transformations in steels in welding conditions at Instytut Spawalnictwa in Gliwice



Rys. 3. Kształt i wymiary próbki stosowanej w badaniach przemian fazowych

Fig. 3. Shape and dimensions of specimen used in tests of phase transformations w funkcji czasu dla zadanych wartości czasu chłodzenia $t_{8 / 5}, s\left(t_{8 / 5}-\right.$ czas chłodzenia symulowanego obszaru SWC stali w zakresie temperatury pomiędzy 800 a $500^{\circ} \mathrm{C}$ ). Kształt i wymiary próbek przedstawiono na rysunku 3.

W związku z dużą dynamiką procesu, podczas badań wykonywanych na stanowisku pokazanym na rysunku 2 zastosowano aparaturę kontrolno-pomiarową firmy National Instruments pracującą w systemie czasu rzeczywistego. Oprogramowanie sterująco-pomiarowe stanowiska badawczego zostało wykonane w środowisku LabView RT (Real Time). Przetwarzanie i analizę krzywych pomiarowych, wyznaczanie temperatury początku i końca przemian fazowych oraz konstruowanie wykresów CTP ${ }_{C}-S$ wykonano w TPF 3.0.

\section{Program TPF 3.0 - przeznaczenie i możliwości}

Program TPF (Temperatury Przemian Fazowych w SWC stali podczas spawania), którego winietę startową przedstawiono na rysunku 4, powstał podczas realizacji projektu badawczego własnego Instytutu Spawalnictwa w Gliwicach [3], a w następnych latach był rozwijany.

Program TPF służy do wyznaczania wartości temperatur krytycznych przemian fazowych w stalach i konstruowania wykresów CTP $_{C}-\mathrm{S}$. W tym artykule posłużono się przykładami dotyczącymi badań przemian fazowych w stali konstrukcyjnej S355JR, która stanowi popularny materiał do wytwarzania konstrukcji spawanych.

Praca z programem TPF rozpoczyna się od wyboru i otwarcia pliku z danymi pomiarowymi (zarejestrowanymi i zgromadzonymi w aparaturze kontrolno-pomiarowej stanowiska badawczego) badanej stali dla odpowiedniej wartości czasu chłodzenia $t_{8 / 5}$ (rys. 5).

Analizę danych pomiarowych (strumienia magnetycznego i dylatacji) przeprowadza się na krzywych przedstawionych w funkcji temperatury (rys. 6).

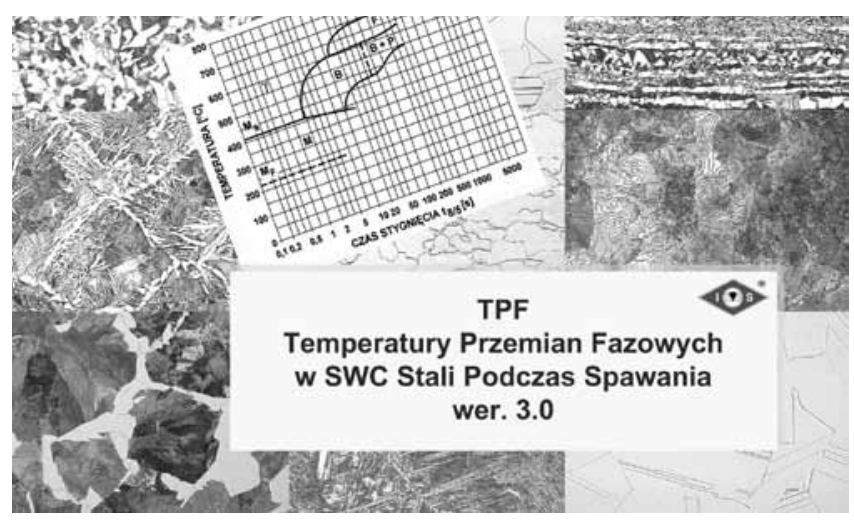

Rys. 4. Winieta startowa programu TPF 3.0

Fig. 4. Opening window of TPF 3.0 software 

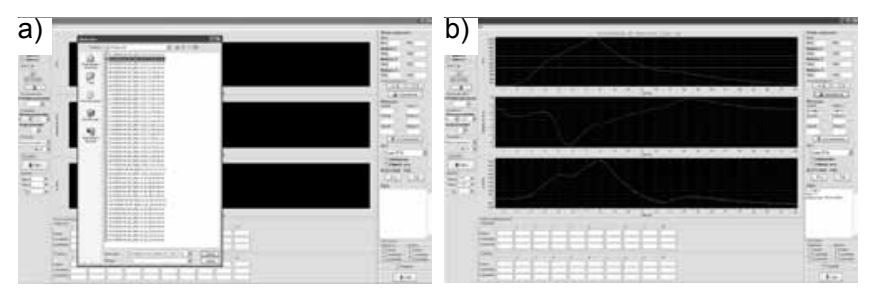

Rys. 5. Okna robocze programu TPF: a) wybór pliku z danymi pomiarowymi do analizy, b) krzywe pomiarowe (w kolejności od góry): temperatury, strumienia magnetycznego i dylatacji (rozszerzalności termicznej) Fig. 5. Working windows of TPF software: a) selection of a file containing measured data for analysis, b) measurement curves (sequence from above): temperature, magnetic flux and dilatation (thermal expansion)

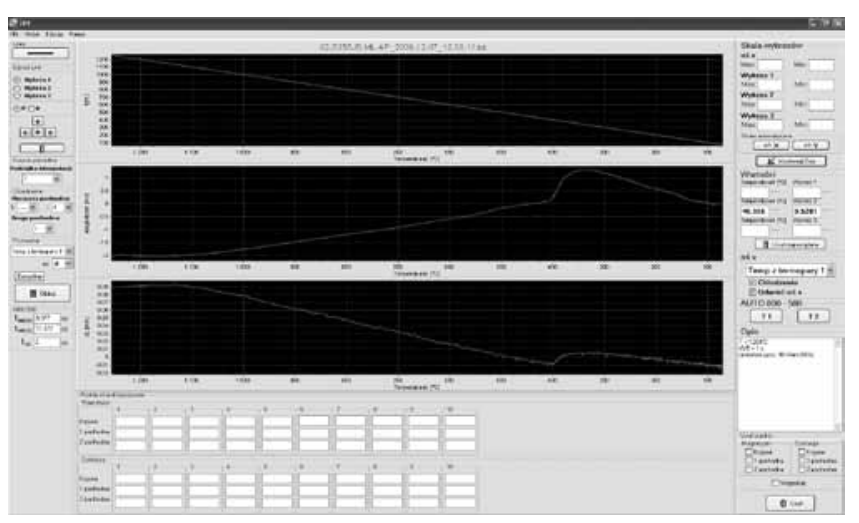

Rys. 6. Krzywe pierwotne: temperatury, strumienia magnetycznego i dylatacji w funkcji temperatury

Fig. 6. Primary curves: temperature, magnetic flux and dilatation in the temperature function

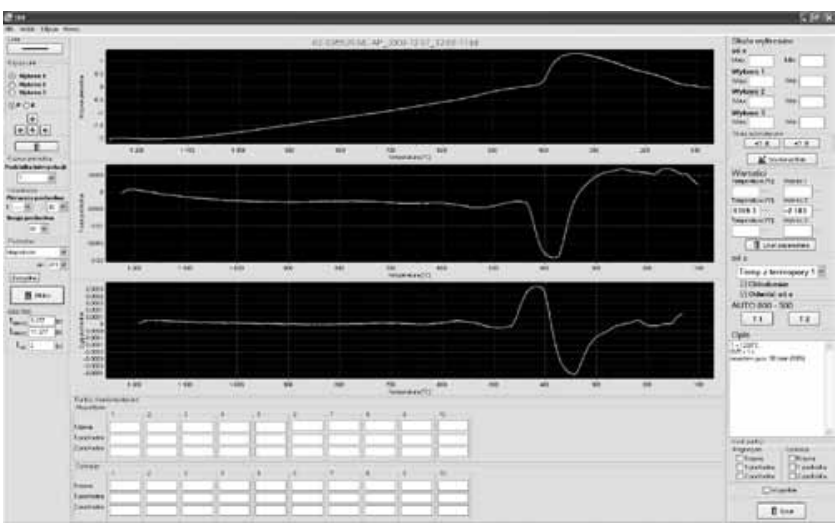

Rys. 7. Przykład krzywych strumienia magnetycznego w funkcji temperatury (w kolejności od góry): krzywa pierwotna, pierwsza pochodna, druga pochodna

Fig. 7. Example of curves of magnetic flux (sequence from above): primary curve, first derivative, second derivative
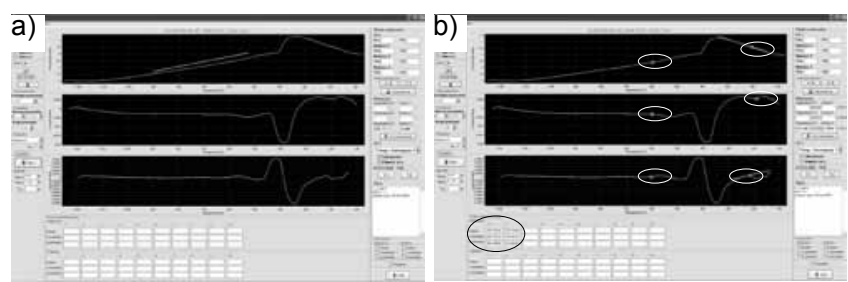

Rys. 8. Sposób określania punktów charakterystycznych na krzywej pierwotnej, I i II pochodnej strumienia magnetycznego: a) prowadzenie stycznej do krzywej, b) wyznaczenie wartości temperatury początku i końca przemiany fazowej

Fig. 8. Procedure of determination of characteristic points on primary, first and second derivative curves of magnetic flux: a) draw tangent to curve, b) determination of start and finish temperature value of the phase transformation
Jeżeli niezbędne jest dokładniejsze uwidocznienie charakterystycznych miejsc (punktów przegięcia) na pierwotnych krzywych pomiarowych, program TPF 3.0 umożliwia ich przekształcenie do postaci I i/lub II pochodnej. W tym celu użytkownik programu ma do dyspozycji rozwijalne menu wyboru: rodzaju krzywej pomiarowej pierwotnej (strumienia magnetycznego lub dylatacji) oraz współczynnika uśredniania dla I i II pochodnej.

Na rysunku 7 przedstawiono widok przykładowych krzywych strumienia magnetycznego po transformacji na I i II pochodną.

Punkty charakterystyczne na krzywych pomiarowych, które odpowiadają temperaturze początku i końca poszczególnych przemian fazowych, wybiera się przez poprowadzenie linii stycznych do krzywych pomiarowych i ustalenie punktu odchylenia stycznej od krzywej pomiarowej (rys. 8).

W czasie wyznaczania poszczególnych punktów charakterystycznych przemian na krzywych pomiarowych program TPF automatycznie gromadzi wartości temperatury krytycznej, co pokazano na rysunku 8b. W analogiczny sposób, jak dla krzywej strumienia magnetycznego, wyznacza się punkty charakterystyczne na krzywych pomiarowych dylatacji (rys. 9).

W rezultacie analizy krzywych pomiarowych dla całego zakresu badanych czasów chłodzenia $t_{8 / 5} u z y-$ skuje się zestawienie wartości temperatury krytycznej poszczególnych przemian fazowych, które program TPF generuje w postaci tablicy zbiorczej (rys. 10).

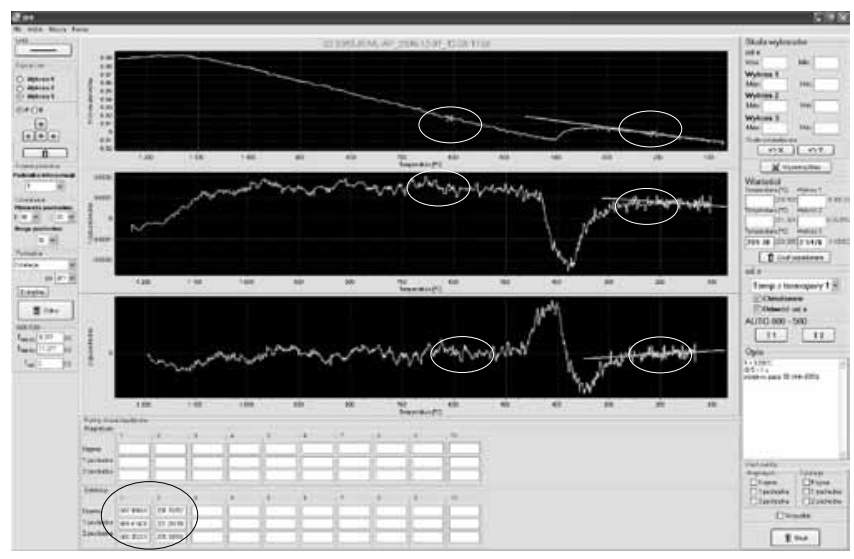

Rys. 9. Wartości temperatury krytycznej przemiany fazowej wyznaczone na krzywej pierwotnej oraz I i II pochodnej dylatacji

Fig. 9. The transformation critical values determined for primary, first and second derivative dilatation curves

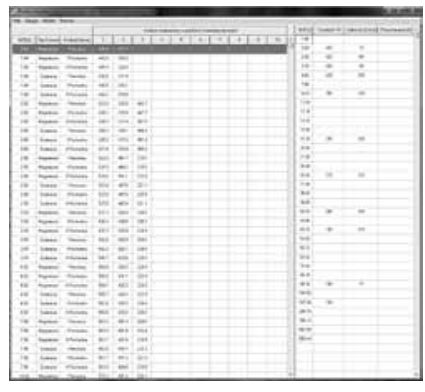

Rys. 10. Tablica zbiorcza zawierająca zestawienie wartości temperatury krytycznej przemian fazowych $w$ badanej stali oraz wartości twardości i udarności w funkcji czasu chłodzenia $t_{8 / 5}$

Fig. 10. Cumulative table with critical temperatures of phase transformations in tested steel and values of hardness and impact strength in function cooling time $t_{8 / 5}$ 




Rys. 11. Okno edycji wykresów $C T P_{C}-S$ w programie TPF 3.0 z wczytanymi wartościami temperatury krytycznej przemian fazowych Fig. 11. The edition window of TPF program for CCT diagrams for welding conditions with read in values of critical temperatures of transformations



Rys. 12. Menu „Ustawienia” w module edycji wykresów CTP $_{C}-\mathrm{S}$ w programie TPF 3.0

Fig. 12. Menu „Settings" for edition of CCT diagram for welding conditions in TPF 3.0 software

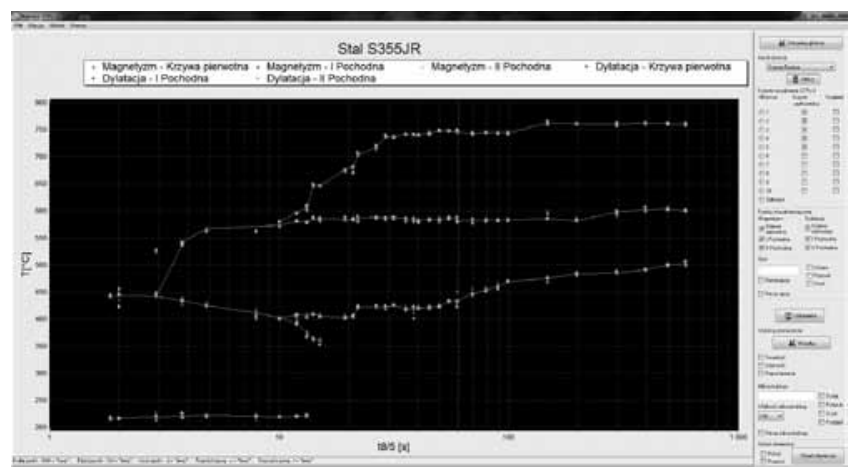

Rys. 13. Edycja punktów charakterystycznych przemian w trybie łączenia odcinkami prostej „od punktu do punktu”

Fig. 13. Edition of characteristic points of phase transformations in mode joining line segments "from point to point”



Rys. 14. Krzywe użytkownika po aproksymacji przy użyciu krzywych Beziera

Fig. 14. User curves after approximation by Bezier’s curves
Tablica zbiorcza stanowi zbiór danych źródłowych do zbudowania wykresu przemian $\mathrm{CTP}_{\mathrm{C}}$-S. Jeśli znane są informacje dodatkowe dotyczące np. rozkładu twardości HV, udarności KCV i/lub pracy łamania KV symulowanego obszaru SWC badanej stali w funkcji czasu chłodzenia $t_{8 / 5}$, to użytkownik również może je umieścić w tablicy zbiorczej w celu wygenerowania przez TPF wykresów uzupełniających.

TPF 3.0 zawiera odrębny moduł służący do budowania i edycji wykresów przemian austenitu CTP $_{\mathrm{C}}-\mathrm{S}$. $\mathrm{Na}$ rysunku 11 przedstawiono okno edycji wykresów CTP $_{\mathrm{C}}-\mathrm{S}$.

Podczas edycji wykresu użytkownik ma do dyspozycji menu „Ustawienia”, za pomocą którego ma możliwość określania np. rodzaju, rozmiaru i koloru czcionki opisu obszarów na wykresie oraz tytułu wykresu, wartości minimum i maksimum na osiach $\mathrm{x}$ i y, koloru tła wykresu (czarne lub białe) itp. (rys. 12).

Przy użyciu dostępnych narzędzi oferowanych przez program TPF użytkownik dokonuje w kolejnych etapach pracy edycji wykresu przemian CTP $_{\mathrm{C}}-\mathrm{S}$ polegającej na łączeniu punktów charakterystycznych odcinkami techniką „od punktu do punktu” (rys. 13).

Następnie, po wyborze z odpowiedniego menu sposobu aproksymacji krzywych użytkownika przy użyciu funkcji liniowej, funkcji wielomianowej lub krzywych Beziera (opcja do wyboru), użytkownik dokonuje „wygładzenia” krzywych na wykresie CTP $_{\mathrm{C}}-\mathrm{S}$ (rys. 14).

Program TPF 3.0, oprócz wykresu podstawowego $\mathrm{CTP}_{\mathrm{C}}-\mathrm{S}$, umożliwia również automatyczne generowanie wykresów uzupełniających dotyczących rozkładu twardości HV i udarności KCV badanej stali w funkcji czasu chłodzenia $\mathrm{t}_{8 / 5}$. Na rysunku 15 przedstawiono

a)

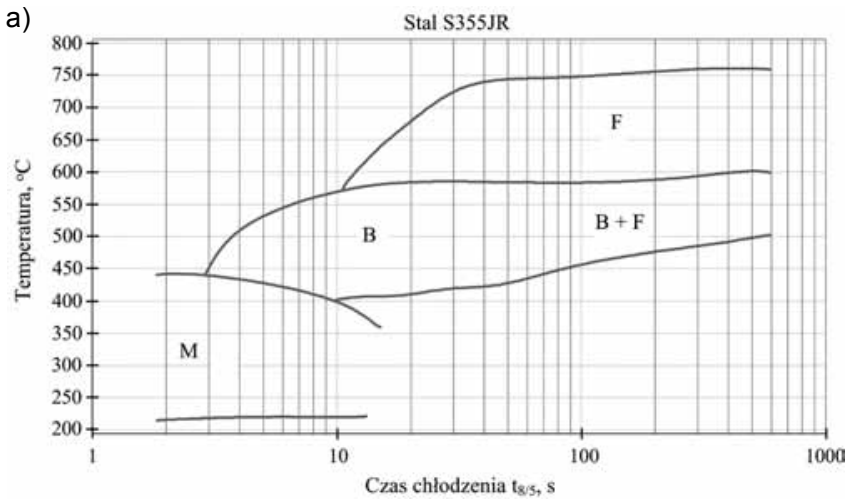

b)

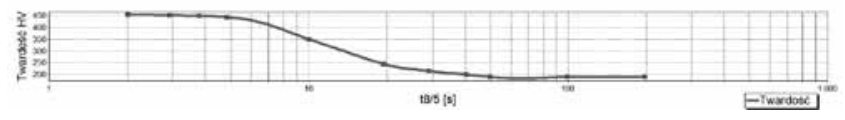

c)

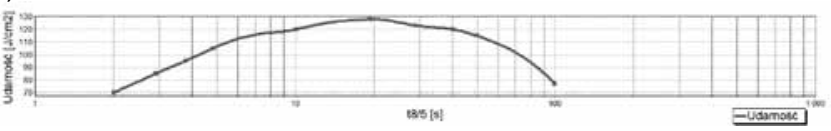

Rys. 15. Przykład wykresu $C T P_{C}-S$ dla stali $S 355 J R$ : a) wykres główny: M - martenzyt, B - bainit, F - ferryt, b) wykres twardości, c) wykres udarności

Fig. 15. Example of CCT (Continuous Cooling Transformation) diagram for welding conditions for S355JR steel: a) main diagram: $\mathrm{M}$ - martensite, $\mathrm{B}$ - bainite, $\mathrm{F}$ - ferrite, $\mathrm{b}$ ) hardness diagram, c) impact strength diagram 
przykład wykresu CTP -S wraz z wykresami dodatkowymi dla stali S355JR.

Ponadto moduł edycji wykresów CTP $_{\mathrm{C}}$-S programu TPF 3.0 umożliwia umieszczanie na wykresie głównym mikrostruktur poszczególnych obszarów strukturalnych oraz tablicy ze składem chemicznym badanej stali.

Ze względu na różnice pomiędzy cyklem cieplnym spawania a cyklem tradycyjnej obróbki cieplnej, o których wspomniano we wstępie artykułu, dokonano porównania wykresu przemian fazowych dla warunków spawalniczych $\mathrm{CTP}_{\mathrm{C}}$-S i wykresu przemian sporządzonego dla warunków metalurgicznych $\mathrm{CTP}_{\mathrm{C}}$ (rys. 16).

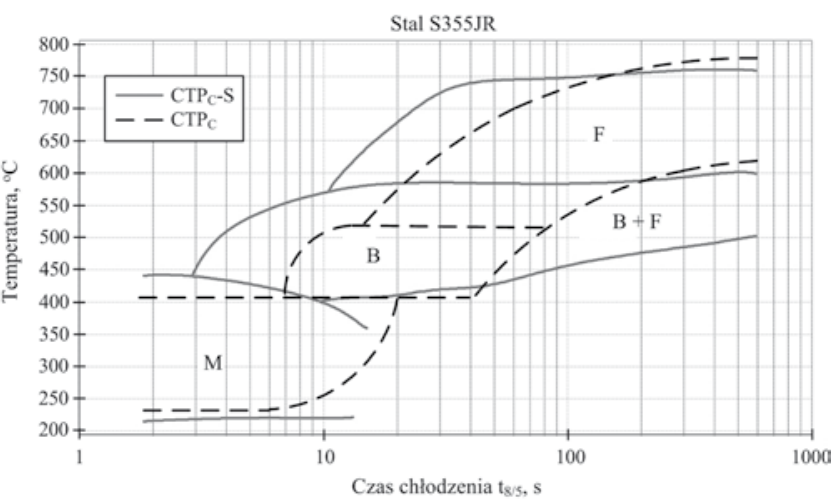

Rys. 16. Porównanie wykresu CTP $\mathrm{C}_{\mathrm{C}}-\mathrm{S}$ z wykresem $\mathrm{CTP}_{\mathrm{C}}[4]$ dla stali S355JR

Fig. 16. CCT for welding conditions diagram compared with CCT diagram [4] for S355JR steel

\section{Podsumowanie}

Z porównania wykresu CTP $_{C}-S$ z wykresem CTP $_{C}$, zamieszczonych na rysunku 16, widać, że występuje duże podobieństwo pod względem ogólnego charakteru krzywych i obszarów strukturalnych. Natomiast są widoczne różnice, które dotyczą usytuowania krzywych względem osi temperatury.

W warunkach spawalniczych przemiany fazowe austenitu w stalach w stanie stałym zachodzą w szerszych zakresach temperatury, tzn. rozpoczynają się w wyższej temperaturze, a kończą w niższej w porównaniu do warunków metalurgicznych. Różnice te wynikają przede wszystkim z różnych wartości temperatury austenityzowania stali (wyższa dla warunków spawalniczych), różnych czasów austenityzacji (dla warunków spawalniczych czasy te są krótsze od $1 \mathrm{~s}$, a dla warunków metalurgicznych wynoszą powyżej kilkunastu minut), różnych długości czasów chłodzenia i warunków chłodzenia badanych stali, a także różnych składów chemicznych (w ramach danego gatunku stali), dla których wykonywano oba rodzaje wykresów.

W związku z tym zaleca się, aby przy projektowaniu technologii spawania, a zwłaszcza przy określaniu temperatury wstępnego podgrzewania przed spawaniem oraz doborze parametrów obróbki cieplnej złącza po spawaniu, korzystać z informacji wynikających $z$ wykresów spawalniczych CTP $_{C}-S$. Pozwoli to uniknąć błędów technologicznych oraz ograniczyć ryzyko występowania pęknięć w złączach spawanych ze stali konstrukcyjnych.

Biorąc pod uwagę dotychczasowe doświadczenie w stosowaniu programu TPF $3.0 \mathrm{w}$ badaniach przemian fazowych w stalach można stwierdzić, że dzięki temu programowi poprawiła się efektywność oraz jakość tych badań.

\section{Literatura}

[1] Pilarczyk J., Pilarczyk J.: Spawanie i napawanie elektryczne metali. Wydawnictwo Śląsk, Katowice, 1996.

[2] Łomozik M.: Metaloznawstwo i badania metalograficzne połączeń spawanych. Wyd. II, Instytut Spawalnictwa, Gliwice, 2011.
[3] Mikno Z., Grzesik B., Łomozik M., Zeman M., Pilarczyk A.: Opracowanie systemu i metodyki pomiarowej w badaniach przemian strukturalnych w stalach w warunkach cykli cieplnych spawania. Projekt badawczy własny nr N505 002 31/0255, 2006-2009.

[4] Orlich J., Pietrzeniuk H.J.: Atlas zur Wärmebehandlung der Stähle. 3, Dusseldorf, 1973.

\section{W następnym numerze}

W następnym numerze opublikowane zostaną artykuły prezentowane na XVII Konferencji Spawalniczej „Spawanie w energetyce” w Jarnołtówku. 